\title{
BMJ Open How do workplaces, working practices and colleagues affect UK doctors' career decisions? A qualitative study of junior doctors' career decision making in
} the UK

\author{
Sharon Spooner, ${ }^{1}$ Emma Pearson, ${ }^{2}$ Jonathan Gibson, ${ }^{3}$ Kath Checkland ${ }^{1}$
}

To cite: Spooner S, Pearson E, Gibson J, et al. How do workplaces, working practices and colleagues affect UK doctors' career decisions? A qualitative study of junior doctors' career decision making in the UK. BMJ Open 2017;7:e018462. doi:10.1136/ bmjopen-2017-018462

- Prepublication history for this paper is available online. To view these files, please visit the journal online (http://dx.doi org/10.1136/bmjopen-2017018462).

Received 30 June 2017 Revised 7 September 2017 Accepted 11 September 2017

CrossMark

${ }^{1}$ Division of Population Health, Health Services Research and Primary Care, School of Health Sciences, University of Manchester, Manchester, UK ${ }^{2}$ Department of Psychology, Edge Hill University, Ormskirk, Lancashire, UK

${ }^{3}$ Division of Population Health, Health Services Research and Primary Care, Centre for Health Economics, University of Manchester, Manchester, UK

Correspondence to Dr Sharon Spooner; sharon.spooner@manchester. ac.uk

\section{ABSTRACT}

Objectives This study draws on an in-depth investigation of factors that influenced the career decisions of junior doctors.

Setting Junior doctors in the UK can choose to enter specialty training (ST) programmes within 2 years of becoming doctors. Their specialty choices contribute to shaping the balance of the future medical workforce, with views on general practice (GP) careers of particular interest because of current recruitment difficulties. This paper examines how experiences of medical work and perceptions about specialty training shape junior doctors' career decisions.

Participants Twenty doctors in the second year of a Foundation Training Programme in England were recruited. Purposive sampling was used to achieve a diverse sample from respondents to an online survey.

Results Narrative interviewing techniques encouraged doctors to reflect on how experiences during medical school and in medical workplaces had influenced their preferences and perceptions of different specialties. They also spoke about personal aspirations, work priorities and their wider future. Junior doctors' decisions were informed by knowledge about the requirements of ST programmes and direct observation of the pressures under which ST doctors worked. When they encountered negative attitudes towards a specialty they had intended to choose, some became defensive while others kept silent. Achievement of an acceptable work-life balance was a central objective that could override other preferences. Events linked with specific specialties influenced doctors' attitudes towards them. For example, findings confirmed that while early, positive experiences of GP work could increase its attractiveness, negative experiences in GP settings had the opposite effect.

Conclusions Junior doctors' preferences and perceptions about medical work are influenced by multiple intrinsic and extrinsic factors and experiences. This paper highlights the importance of understanding how perceptions are formed and preferences are developed, as a basis for generating learning and working environments that nurture students and motivate their professional careers.
Strengths and limitations of this study

- Use of narrative interviews facilitated an in-depth exploration of what drives specialty choice for junior doctors.

- Interviews were conducted during the period when specialty recruitment was in progress.

- Doctors were encouraged to include a wide range of factors based on personal preferences and experiences.

- We cannot comment on how patterns of career choice may be affected by personality types or whether participants remained fixed on their specialty choice.

- While purposive sampling aimed to achieve diversity among participants, it is possible that other doctors may have different perspectives.

\section{INTRODUCTION}

In the UK, the NHS is responsible for delivery of comprehensive health services in community and hospital settings. Continually evolving national and local organisational structures mean that managers and clinicians must continually adjust their working practices. ${ }^{12}$ Organisational changes influence how medical work is monitored, managed and commissioned. They also shape the environments in which medical students and junior doctors acquire medical knowledge and skills and competencies that are essential in their future work. ${ }^{3}$ Workplaces, working practices and colleagues influence how newly qualified doctors develop a sense of professional identity, which acts as a platform for confident and professional practice, and informs how they respond to positions of responsibility in challenging and unfamiliar situations. ${ }^{4-6}$ Furthermore, factors such as gender, location and preferences related to the sort of patients they wish to work with influence 
junior doctors' career decisions as they progress towards specialist training. ${ }^{78}$

Studies of medical students' experiences in specific specialties indicate that positive experiences are associated with greater desire to enter that specialty. ${ }^{9}$ However, students who do not enjoy working with specific patient groups (eg, elderly patients) are not necessarily attracted to do so unless they become convinced of the positive aspects of that specialty. ${ }^{10}$ Discrete choice experiment studies have indicated that while medical students primarily value good working conditions, junior doctors also value good opportunities for partners and a desirable geographical location. ${ }^{11}{ }^{12}$ However, these studies are unable to elicit detailed information about which aspects of workplaces, working practices or the experiences gained through observing colleagues exert most influence on doctors' specialty choice.

Employment of a workforce equipped with appropriate training and resources is an essential component of providing timely and high-quality care for patients. ${ }^{13} 14$ Since the cumulative effects of junior doctors' individual decisions as to which specialty they wish to pursue have long-term implications for achieving a balanced future workforce, their choices are of heightened importance in the context of concerns about UK medical recruitment across a diverse range of specialties. ${ }^{15-18}$ In recent years, an increasing proportion of doctors have chosen not to progress directly to specialty training (ST) programmes, with rising preferences to defer training, move abroad or leave medical work. ${ }^{19} 20$

Since the implementation of a new career structure, Modernising Medical Careers (MMC) in 2005-2006, ${ }^{21}$ doctors in the UK begin specialty training 2 years after graduation. While it is known that many doctors move from one specialty to another, training programmes are relatively inflexible, and switching ST programmes can incur financial penalties; therefore, it is important that young doctors choose wisely. ${ }^{22}$ Studies have shown that medical students' lifestyles and social circumstances affect the relative importance of income and status. They are also affected by family attitudes and are more likely to choose specialties in which they have had clinical placements. ${ }^{23-25}$

While the proportions of doctors appointed in each ST programme are published annually by Health Education England, these data do not reveal whether doctors have been successful in achieving their preferred ST choice. Further, they provide no information about how or why doctors have made those decisions and nuanced evidence about the factors associated with individual specialties that attract or deter junior doctors is, therefore, limited.

This study looks in detail at the background factors that were most influential for Foundation Programme doctors (F2s) as they neared completion of an initial 2-year training programme (Foundation Programme) and considered what to do next. Because of an ongoing shortfall in the proportion of doctors entering general practice specialty training (GPST), and concerns about
GP workforce retention, this study focused primarily on attitudes to GP work as expressed by doctors choosing and not choosing GP careers. ${ }^{26}$ These factors included their experience of workplaces, working practices and colleagues and the importance of finding a balance between their medical work and other priorities.

\section{METHODS}

This study consisted of two data-gathering components. In the first phase, we requested that staff at Foundation Schools in England relay a message to their F2 doctors that invited them to complete an online survey about their career intentions and preferred job characteristics. Doctors who completed the survey could opt to receive information about further participation through interviews focusing on what had influenced their career choices. Full participant information was supplied and consent obtained in advance and in accordance with Ethics Committee approvals.

During the second phase of the study, interview participants were purposively selected from $225 \mathrm{~F} 2$ potential interviewees; a range of demographic and career intention responses were used to achieve a diverse sample of interviewees. An open, narrative-inducing approach encouraged doctors to reflect on their perceptions of medical careers and about what had affected their choices. Face-to-face interviews were audio-recorded and generally continued for around 1 hour and were professionally transcribed. Interviewing ended when no additional themes continued to emerge after completion of 20 interviews. Details on gender, specialty preference and length of interviews for each participant are given in table 1 where each participant's Study ID prefix indicates their reported preference for GP specialty training: GP1=GPST first choice, GP2=GPST second choice and GP0=GPST not chosen.

Since the primary objective of this study was to explore the reasons behind doctors' choice of medical specialty training, data reflect topics and attitudes as expressed by participants during open interviews and, where necessary, in response to a general question about GP. The balance of data reflects this overall research orientation.

Themes were identified following coding using NVivo software and an inductive approach to semantic thematic analysis, following steps set out by Braun and Clark. ${ }^{27}$ These themes were reviewed, defined, collapsed, split and omitted as necessary throughout the process of analysis. They illustrate the importance of both perceived and observed working practices during both medical school and foundation training, suggesting that working practices are an influential component of specialty career choice.

\section{RESULTS}

Findings are presented under broad headings linked with themes that were prominent across interviews: career 
Table 1 Interview participants' gender, specialty preferences and interview duration

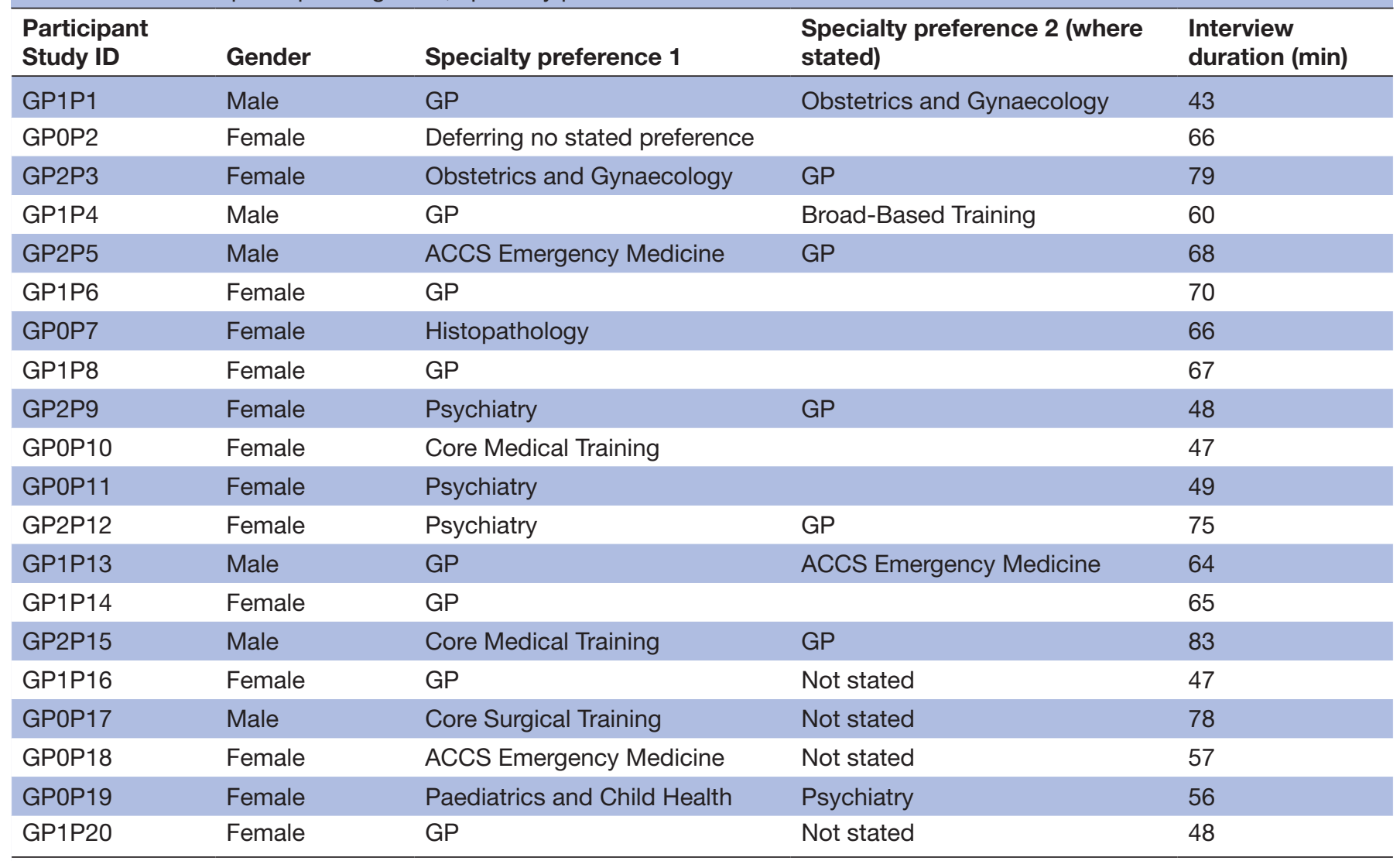

ACCS, Acute Care Common Stem; GP, general practice.

structures and pathways (what do the different careers look like?), the realities of work routines (what will my routine be, and can I cope with it?), considering job status and future prospects (is this job sustainable and stable?), the impact of work on life (how will my future look if I work in this field, and is that what I want?) and the adequacy of preparation for choosing a specialty (how can I know which specialty will suit me best?).

\section{Career structures and pathways}

Since the introduction of the MMC programme, doctors in the UK typically enter training programmes (3-8years) in their chosen specialty following Foundation Programme training (or other approved training). By working alongside specialty trainees, medical students and Foundation doctors become familiar with the training requirements, working practices and opportunities associated with various specialty careers.

These experiences are important in informing opinions about which specialties seem most attractive, but it is not possible to gain first-hand experience of all specialities; interviewees reported dissatisfaction that their career decisions were therefore based on limited information. Some reported that feeling welcomed and integrated during short 'taster' periods in various specialties could be inspirational experiences that influenced their career choices, but access problems hampered extended visits to other specialties such as GP:
The taster I think helped me because it gave me an idea of what... the kind of people would be like, see what the patients would be like. That, kind of, made me think-yes, I could probably do this... I really felt like they tried to, like, integrate me into the team.' (GP0P11)

If you're really interested in the [hospital] specialty that you do as a medical student you can get more involved, so you can stay later or you can volunteer to do things... Whereas, in GP, I felt like you went for the day and you came back. (GP2P3)

Doctors recognised contrasting attitudes to specific specialties; some ST programmes were viewed as highly structured, intense, competitive and demanding high motivation, while others were rated as unworthy or unexciting:

I like structure, and I like to know where I'm going... I want to move up the ladder, I want to acquire skills. (GP0P17)

A lot of the best candidates go for very competitive specialties... because a lot of medics are competitive, by nature they're very driven people and they like to do the best thing; so when something is portrayed as a lesser thing then I think almost psychologically they're less inclined to go for it. (GP1P4) 
Recent changes to junior doctors' contracts have increased career uncertainty for this cohort leading to shifts in the attractiveness of individual ST programmes. ${ }^{20}$ GP specialist trainees (GPSTs) currently have a shorter training programme than other specialities, and some said that this meant earlier opportunities to feel in control of their future:

Three years' training is the minimum which they [GPSTs] could do to get a job which would then allow them that freedom to either move or to determine their own contract... So I think if anything perhaps the contract has pushed people towards GP just because of the training period, giving them perhaps freedom a little bit earlier. (GP2P12)

Because GP is just short training... if I did want to do something else at a later date, I've still got time. (GP1P20)

However, while GP training was highly rated and doctors recognised it as more compatible with other priorities, many regarded GP as nothing better than a reserve option:

I never heard anyone say, oh, it's great to be a GP, you're going to be a fully-fledged GP in three years if you stick at it... which is surprising... You can go and work wherever you want, instead of having to wait for the one gastro post that might turn up in five years in the place that you want it. (GP1P16)

There was an image of a GP as being somebody who's, kind of, failed every other speciality, not able to get into a speciality, so they've given up, they've become a GP... and it subconsciously roots into your mind. (GP1P13)

Thus, in summary, doctors reported that medical school and early work furnished them with partial information about possible careers and recognised that hierarchical attitudes, contractual issues, competitiveness and known structural elements influenced their views.

\section{The observed realities of work}

Interviews revealed that perceptions based on observing or assisting with medical work as a student were often significantly different to the experience of being a doctor:

I hated my job [psychiatry] but I loved it as a student... I just found it really depressing as a doctor whereas as a student I found all the stories really interesting. (GP0P18)

I don't think you get the same experience as a medical student as you do as a junior doctor, no matter how much they try to, because you just don't have that same responsibility. (GP2P12)

Doctors tended to feel drawn towards supportive teams and teachers who engaged with or inspired them, or helped rebuild their damaged confidence:
I met a few people there [psychiatry] who were really encouraging and also were really passionate about the work... I'd say that was the one thing where there [were] people involved that I thought this is what I want to do. (GP0P11)

One of the consultants... went through my portfolio with me... he'd bring me along, he'd teach me, he'd let me get involved. He was absolutely a mentor. (GP0P17)

In my GP placement, had an amazing supervisor that was just really supportive and gave me feedback how it should have been given, and just kind of coaxed me through and built up my confidence again. (GP0P2)

However, workplaces varied and sometimes a heavy workload meant there was less time for teaching; at times, junior doctors felt inadequately supported for difficult work:

People were working 40, 50 hours a week, staying till eight, kind of thing, and other people were doing literally nine-to-five. (GP0P2)

In stroke, the consultants were there in the morning, for an hour, for ward rounds, and then disappeared... whereas in a lot of other specialities, they gave us their mobile numbers, or they said, don't hesitate to contact us... similarly, our SHOs... took a bit of a step back. And I just didn't feel as supported... It was very hard work, it was very intense. (GP0P17)

I don't think there was any support per se [in GP]. Like, if you asked a question they'd tell you the answer, but that's not support, is it? (GP1P16)

Doctors reported feeling underprepared for tasks they were asked to perform or to cope with terminally ill patients. However, it became clear through doctors' narratives that working in specialist teams that were supportive in nature could transform a new or worrying situation into a positive experience:

On both paediatrics and ENT, the consultants were very, very involved. So, if a consultant turned up on the ward, and you were struggling, it didn't matter whose patient they were, it didn't matter whether they were on call, they would go, 'x, are you okay? what can I do?'. And that makes a huge difference. (GP0P17)

Doctors reported positively on periods spent in GP; of being able to manage their own consultations, feeling included in the practice team, and enjoying a wide range of conditions and types of patients:

I felt part of the [GP] team. It gave me a chance to see patients on my own; there were always people there to ask questions about... I did definitely feel integrated in that it was a useful experience. (GP0P11)

I quite liked the variety and there wasn't a specific specialty that I could see myself doing for the rest of 
my life, just that specialty... I quite like the, sort of, general side and looking after people as a whole and just, sort of, yeah, treating them as a whole person rather than just thinking about their heart or their lungs or... able to think about lots of different things. (GP1P20)

However, much as they appreciated the positive challenges of GP work, some worried about finding ' $a$ really nice practice', did not feel ready to leave the hospital roles in which their skills were kept sharp, felt uncomfortable in managing the intrinsic uncertainties of primary care or if regular working hours would be achievable:

Even being in GP for those four months... dealing with, sort of, different, more chronic conditions and I really hated that I'd lost confidence, I'd forgotten things, I didn't feel as confident with poorly patients. (GP0P10)

I worried a lot more [in GP], because if, say for example, on my ward jobs I thought, oh, I've forgotten to do something with...one of my patients, I can either ring up the hospital at 11 o'clock at night and it will get done or if I completely forget, it will probably get picked up by somebody else. (GP0P10)

With A\&E you finish your shift and you go home, with GP you finish your surgery and then you do your clinic referrals and you do your letters and you do everything else and then eventually you get home and then you have other stuff to do and it just seems to take over your life. (GP0P18)

Interviewees drew on a pool of first-hand and other experience in weighing up the pros and cons of specialty careers. The variability of these accounts suggested that real-life work experience was important in their decision making and that prospective colleagues and patient groups were also important. However, individual doctors reported both positive and negative impressions of the same specialty and expressed concern that it may be difficult to obtain a post which was exactly as they wanted.

\section{Perceived status of specialty and future prospects}

Doctors confirmed first-hand experience of denigration of GP work by hospital specialists and reported how this had altered how they had been treated after expressing an interest in training for GP. Examples illustrate the reactions of senior hospital doctors and how a junior doctor had kept quiet to avoid being badly thought of or excluded from 'specialist' teaching:

When I told her [oncologist] I was going to be a GP, she looked at me and she said, oh, are you pregnant? (GP1P16)

Oh, why do you want to do [GP]?'... it just seemed a boring pursuit for them... it put me off a bit. I mean because I didn't want to be thought of as the one who wasn't trying hard... or wasn't going to like put their hand up for something that maybe wouldn't be relevant to my future. (GP1P14)

Experience of watching how GPs work had convinced some that such attitudes were misplaced. Instead, doctors spoke of respecting GPs for their 'really, really tough job' (GP0P10). Another spoke of the added significance of supportive comments from a hospital consultant whose pro-GP career opinions were valued more because his wife was a GP:

someone bothering to say that who was a hospital doctor meant more to me than a GP saying it because GPs... It just was like someone countering the wave of negativity in the hospital about being a GP, so I held onto that. (GP1P14)

In addition to negative attitudes towards a GP career, evidence emerged that psychiatry also suffers from low regard; for example, some doctors spoke of a medical parent having advised against it 'because it's not real medicine'. GP0P18 and another prospective psychiatry trainee felt a great deal of pressure to make 'a responsible decision to do GP' GP2P9.

Doctors expressed mixed views on the extent to which the attitudes of their families, friends or other people influenced their specialty choice. In some cases, status and respect were significant influences, while others attached greater importance to achievement of a worklife balance that was acceptable to family members:

Most people I've said that I want to do psychiatry to, from in the hospital, have looked quite surprised, especially in intensive care, because they're all anaesthetists. It's, 'Why have you chosen psychiatry?' I think that doesn't matter to me so much, because I know that I'd really enjoy it, and it's really important. But, I think, it would bother me if family thought that, you know, I perhaps wasn't around so much because I work, or maybe putting too much into work, and not enough into other things. (GP0P19)

I don't care what my friends and family think, it's the wider population. ... I had the girl doing my nails one day. She said, 'Oh, what kind of doctor are you going to be?' I said, 'I'm going to be a GP'. And she said, 'Oh, do you have to go to medical school for that?' And I just thought, ... there's just that a bit less respect, isn't there, than, 'Oh yes, I'm a brain surgeon. (GP1P16)

While several spoke enthusiastically about pursuing competitive hospital specialties, the prospect of a different junior doctors' contract and sense of being undervalued as a dedicated professional workforce was a source of concern:

I'm just a bit worried that the NHS is such an unknown at the moment in the future and... that's my whole career... But I feel more and more that these people who work in the government are not really respecting us as a profession. (GP1P8) 
Doctors perceived that the new contract conditions would make work more exhausting and, although the shorter training period for GP seemed attractive, they felt that GP work had changed and was also uncertain:

With the way the current contract changes and the way the current health service is, I don't think I'd want to work in an acute specialty anymore because I just think that's the way to a burnout. (GP1P1)

In GP now you don't often see the same people... you only get like five or seven minutes. It's very difficult I think-to...really get to the bottom of what's going on in such a short space of time. (GP0P11)

These attitudinal factors and an undercurrent of uncertainty about specialty choice and future stability in their careers were prominent in doctors' narratives and were consistent with evidence that about half did not intend to proceed directly to any UK specialist training programme.

\section{Achieving a balance between working and living}

Most doctors placed huge importance on achieving a good work-life balance; time for family, friends and exploring interests beyond their specialty or unrelated to medical work were prominent in the narratives of interviewees. When weighing up the relative attractiveness of different specialties, this could be the deciding factor:

I would love to do gastroenterology, but... I just know I wouldn't have a good work-life balance. Work-life balance is really important to me, I'd probably say more so than what I want to do in my career... if I'm not enjoying myself out of work, it's just not worth it for me. (GP0P10)

In addition to compelling personal reasons, doctors were put off by habitually heavy workloads, which contributed to anxiety about their ability to work safely:

The sort of commitment you need for surgery... it wasn't something that I'm interested enough in to want to do. (GP1P20)

Paediatric registrars are incredible, they work phenomenally hard, they have horrendous hours... I don't want to be doing that for the rest of my life, I can't safely practice doing that for the rest of my life. (GP0P17)

Having seen registrars who were 'broken' and consultants present until 23:00, the above doctor switched his career plan to a different specialty to avoid such extended commitment. Others echoed his concern that people choosing 'the more exciting specialties' may feel rather different when they have matured or when their priorities changed:

the speciality that you want to do when you're 25, the lifestyle that you're going to want when you're 25 is not the lifestyle that you're going to want when you're 45. (GP0P18) it needs to be something that I love so much that I'm willing to make the part of my life that is medicine, that chunk more significant, and it's going to eat into other areas of my life... but I see medicine as part of my life, as opposed to my entire life. (GP1P13)

Feeling they need to commit to a career path at this early stage felt premature for some doctors; they were still learning to cope with emotional stress, to spend time listening to patients and appreciated working in settings where colleagues demonstrated similar preferences and rejected teams who acted differently:

Consultants... junior doctors that I've worked with, the registrars and the SHOs, I've felt like they're quite similar to me... they all cared a lot about the patients, they saw them as people not just disease processes and listened. (GP1P6)

I'd like to be around a caring, friendly, supportive team, because that will... I feel like that will make me more caring, supportive and friendly, whereas, in a more direct blunt specialty, that's...I'll definitely become more like that and it's not someone I want to be. (GP2P3)

They weren't interested really, it wasn't their job and I don't really want to be like that, I'd rather listen to what the patient wants and adapt than just stick on my road. (GP2P3)

During these interviews, doctors spoke of their motivation for helping patients, but none referred to work as a vocation. They indicated that while medicine was regarded as a significant part of junior doctors' lives in which they wish to succeed, it is also one that many may seek to contain or control through their career choices.

\section{Career decision changes based on personal experience}

In addition to feeling that it was too early to make longterm career decisions, doctors identified deficiencies in their preparation for choosing between specialties because of limited exposure to specialties and because the full impact of responsibility could not be experienced during medical school. Instead, medical school was remembered as a time of awareness of 'a hierarchy of intelligence of different specialties' (GP2P15). Intense competition was followed by dispersal into Foundation Programme posts with multiple tasks and unpleasant duties:

the realities of the job set in... everything's great when you're a student because you can just walk away an hour before the work's done... when you're dealing with it as a doctor you have to see things through to the end of the day and all the negative experiences and all the arguments with patients and relatives and all the complaints. (GP2P15)

They discovered that levels of clinical knowledge and communication skills that were adequate to pass examinations fell short of what was needed, but with practice and support they could gain confidence: 
[In GP] you have to know about ... management and also guidelines and standards... We didn't really get any of that information, it was really based on the basis of history and examination, these are the kind of things that could be wrong and then later on this is how you can treat them. (GP0P11)

I learned some self-dependence, I learned to trust my own decisions and opinions... it made me focus on my history taking and examination skills, rather than just being so reliant on blood results, and chest x-rays, and scans. (GP0P17)

In GP, doctors could find opportunities to build confidence, use interpersonal skills, deal with variety and have access to a supportive team; this led to positive experiences and a confirmation for some of GP as their preferred specialty:

I think potentially the biggest thing you can do is ensure that people have an experience of it in their foundation training really. (GP2P5)

However, the challenging nature of GP work was also clear to interviewees. Through media reports and their own observations, they detected 'a wave of cynicism and sceptical attitudes' (GP1P14) surrounding GP that could not be ignored:

If you're one of the senior GPs or whatever, you have an influence over the attitude of the people you work with and everyone has a responsibility to create a nice environment to work in. It sounds maybe a bit optimistic and a bit sort of wishy washy, but I hope that you can keep that going for 30 years or 40 years. It just feels like no-one... not many people are still standing there being like, I've been a GP for 40 years and I still love it. No-one's saying that. No-one's saying that. (GP1P14)

The above doctor intended to train for GP despite misgivings that could have been eased by greater positivity from experienced GPs, which underlines the importance of placing students and junior doctors in practices where GPs are ready to communicate the best aspects of their working lives.

\section{DISCUSSION}

In this paper, we have described a number of factors that seem to influence the career decisions of junior doctors.

Structured training programmes for all specialties differ in duration and in the characteristics associated with them. Competition for training posts and the perceived career prospects following successful completion of training were important considerations for many of the participants in this study. Perceptions of specialties and ST programmes generally depended on the personal values and motivations of the individuals and whether they preferred generalist or specialist work.
Having exposure to the specialties of choice was important. Doctors gathered some information through observing specialty trainees, but recognised the added value of working in specialties that were among their preferred choices. However, since this was not possible in all cases, some who were unable to include specific specialties in their Foundation Programme chose to defer a decision until they could make a more informed choice.

Attitudes of others, including peers and senior medical practitioners, friends and family, can influence thoughts and feelings about professions and tended to be discussed in a negative light for specialties such as GP and psychiatry, where negative attitudes of others could lead to hesitation and uncertainty.

Contractual change was believed to affect some specialties to a greater extent than others and led some to switch from their preferred to another specialty to mitigate the effects of that change. There was a general feeling that these changes would affect all UK career choices and concern that work schedules were already threatening the ability of overstretched doctors to work safely. While this did not lead all participants to change their decision to apply to a specialty where they had observed this trend, they expressed fears for the future.

Work-life balance was an important theme, cited by most as a major criterion when planning their careers. Some participants reported a switch in their original aspirations to reflect their life plans outside of work. They placed limits on their willingness to allow their job to impinge on their life as a whole and recognised that if they did not feel comfortable making the investment necessary for a given specialty, they should look elsewhere.

Many narratives demonstrated that doctors' experiences with one specialist team could profoundly shape their opinion of that entire specialty. High levels of support, well-organised teaching, plentiful feedback, encouragement and positive reinforcement were generally categorised by participants as contributing to the attractiveness of a specialty. Where experiences were described in terms of a lack of support for doctors, or disinterest in patients, participants tended to distance themselves from that specialty.

\section{STRENGTHS AND LIMITATIONS}

Individual interviews with F2 doctors from a broad range of personal and educational backgrounds provided in-depth narrative accounts during which doctors reflected on when, where and how they had formed ideas about their future career plans. Conducting interviews at a stage when career decisions were at the forefront of their mind capitalised on this as a topic under active discussion between peers and with senior colleagues. Despite efforts to achieve a diverse sample in terms of chosen specialty, it was not possible to recruit from all specialties due to limitations of participant consent and the scope of the study. Furthermore, we obtained interview data from more female than male doctors; this may in part be due 
to a rising proportion of early career doctors across all specialties who are women and which is more marked in $\mathrm{GP}^{28}$

We did not make any assessments of the doctors' personality traits, aptitudes or other such characteristics and are therefore unable to comment on how these may have influenced their decisions. Furthermore, we are not able to confirm whether they remained firm in decisions they had made or accepted an alternative ST programme. As part of a longitudinal study, further interviews conducted after they have gained further experience of work would usefully add to our analysis of this decision-making process.

\section{LINKS WITH OTHER STUDIES}

A decline in the attractiveness of GP that has been confirmed over a 15 -year period is not unique to the UK and there is broad agreement that doctors' career choices are influenced by both intrinsic (eg, personal attitudes and preferences) and extrinsic (eg, family and environmental) factors. ${ }^{89-32}$ Studies have confirmed that work-related priorities are associated with gender and noted that whilst income and promotion prospects have declined in importance, enthusiasm for their chosen specialty and hours that matched their domestic circumstances have become more important. ${ }^{33} 34$ Furthermore, it has been proposed that matching doctors' preferences to their future work is likely to create a happier medical workforce. ${ }^{30}$ Our findings are well aligned with international studies indicating the recruitment potential for GPST programmes of drivers similar to those also recognised in other specialties; such as early clinical experience of GP work, positive role models and promotion of GP careers. ${ }^{102535}$ However, although these actions are among recommendations of a recent Health Education England Report, ${ }^{36}$ there is limited high-quality evidence demonstrating a durable impact of interventional recruitment strategies (eg, financial incentives, support for doctor well-being, targeted recruitment, focused undergraduate placements, marketing strategies etc). Furthermore, some strategies that produced enhanced attitudes to specific specialties did not translate into altered specialty choice, ${ }^{37-39}$ and there is evidence that choices can be intrinsically personal and idiosyncratic. ${ }^{40}$

\section{CONCLUSIONS}

Understanding the factors that influence junior doctors' career choices is a vital prerequisite for achieving a balanced and sustainable workforce, and in the context of a GP recruitment crisis, this study adds to what is known about what influences affect junior doctors' attitudes to specialty choice and to GP work. A better understanding of these factors will support development of policies and structures that shape workplaces, working practices and relationships within healthcare teams such that sufficient numbers of doctors are attracted to each specialty, including GP, to match healthcare needs and future patterns of service delivery.

This research has highlighted the importance of working experiences, perceptions about how different specialities are viewed and the importance of work-life balance. These findings point to specific and achievable changes that could be instituted in both medical schools and Foundation Programmes to support the long-term goal of a balanced, fit-for-purpose workforce. These include a concerted campaign to ensure that specialists treat other specialities with respect and refrain from denigrating students' choices, ensuring that all Foundation doctors undertake a post in GP as well as a range of hospital specialities, and further developing opportunities for students and Foundation doctors to undertake 'taster' sessions in a wide range of specialities.

Contributors SS led this study, with all authors involved in study design and discussion of data from interviews carried out by EP and SS. All listed authors have directly contributed to writing and finalising the paper.

Funding This paper presents independent research funded by the National Institute for Health Research School for Primary Care Research (NIHR SPCR). The views expressed are those of the authors and not necessarily those of the NIHR, the NHS or the Department of Health.

Competing interests SS reports grants from NIHR SPCR, during the conduct of the study, and also works as an NHS General Practitioner. KC reports grants from NIHR School for Primary Care Research, during the conduct of the study, and grants from Department of Health Policy research programme, outside the submitted work EP reports grants from NIHR School for Primary Care Research, during the conduct of the study; personal fees from additional part-time employment in teaching and research at the University of Manchester, outside the submitted work; JG has nothing to disclose.

Ethics approval University of Manchester Research Ethics Committee 6, Ref: ethics $/ 15370$.

Provenance and peer review Not commissioned; externally peer reviewed.

Data sharing statement Raw transcripts are held by the researchers who will consider requests for further information in line with guidance from funders and/or ethics committee.

Open Access This is an Open Access article distributed in accordance with the Creative Commons Attribution Non Commercial (CC BY-NC 4.0) license, which permits others to distribute, remix, adapt, build upon this work non-commercially, and license their derivative works on different terms, provided the original work is properly cited and the use is non-commercial. See: http://creativecommons.org/ licenses/by-nc/4.0/

(c) Article author(s) (or their employer(s) unless otherwise stated in the text of the article) 2017. All rights reserved. No commercial use is permitted unless otherwise expressly granted.

\section{REFERENCES}

1. Robertson R. Six ways in which NHS financial pressures can affect patient care. The King's Fund. London, 2016.

2. NHS England. Delivering the Forward View: NHS planning guidance 2016. 2015:17-2020.

3. Bleakley A. Pre-registration house officers and ward-based learning: a 'new apprenticeship' model. Med Educ 2002;36:9-15.

4. de Lasson L, Just E, Stegeager N, et al. Professional identity formation in the transition from medical school to working life: a qualitative study of group-coaching courses for junior doctors. BMC Med Educ 2016;16:165.

5. Kilminster S, Zukas M, Quinton N, et al. Preparedness is not enough: understanding transitions as critically intensive learning periods. Med Educ 2011;45:1006-15. 
6. Freidson E. Profession of medicine. A study of the sociology of applied knowledge. New York: Dodd, 1970.

7. Hutt R. Doctors' career choice: previous research and its relevance for policy-making. Med Educ 1976;10:463-73.

8. van der Horst K, Siegrist M, Orlow P, et al. Residents' reasons for specialty choice: influence of gender, time, patient and career. Med Educ 2010:44:595-602.

9. Marshall DC, Salciccioli JD, Walton SJ, et al. Medical student experience in surgery influences their career choices: a systematic review of the literature. J Surg Educ 2015;72:438-45.

10. Meiboom AA, de Vries $\mathrm{H}$, Hertogh CM, et al. Why medical students do not choose a career in geriatrics: a systematic review. BMC Med Educ 2015;15:101.

11. Cleland JA, Johnston P, Watson V, et al. What do UK medical students value most in their careers? A discrete choice experiment. Med Educ 2017;51:839-51.

12. Cleland J, Johnston $P$, Watson $\mathrm{V}$, et al. What do UK doctors in training value in a post? A discrete choice experiment. Med Educ 2016;50:189-202.

13. Addicott R, Maguire D, Honeyman M, et al. Workforce planning in the NHS. 2015.

14. Zurn P, Dal Poz MR, Stilwell B, et al. Imbalance in the health workforce. Hum Resour Health 2004;2:13.

15. Chaudhuri E, Mason NC, Newbery N, et al. Career choices of junior doctors: is the physician an endangered species? Clin Med 2013;13:330-5.

16. Roland $\mathrm{M}$, Everington $\mathrm{S}$. Tackling the crisis in general practice. $B M J$ 2016;352:

17. Ryland $\mathrm{H}$, Baessler F, Casanova Dias $\mathrm{M}$, et al. The psychiatry recruitment crisis across Europe: evaluation by the European Federation of psychiatric trainees. European Psychiatry 2016;33(Suppl):S285.

18. El-Sheikha S. Surprised an A\&E is closing because of doctor shortages? We warned you we would leave-now it's happening 2016. http://www.independent.co.uk/voices/nhs-hospital-closingaccident-emergency-department-junior-doctors-contract-jeremyhunt-theresa-may-a7185041.html.

19. UK Foundation Programme Office. The foundation programme career destination report 2016. 2017.

20. Spooner S, Gibson J, Rigby D, et al. Stick or twist? Career decisionmaking during contractual uncertainty for NHS junior doctors. BMJ Open 2017; 7:e013756.

21. Department of Health. Modernising medical careers: the next steps: the future shape of foundation. Specialist and general practice training programmes: Department of Health 2004.

22. Goldacre MJ, Laxton L, Lambert TW. Medical graduates' early caree choices of specialty and their eventual specialty destinations: UK prospective cohort studies. BMJ 2010;341:c3199.

23. Heiligers PJ. Gender differences in medical students' motives and career choice. BMC Med Educ 2012;12:82.
24. Maiorova T, Stevens F, Scherpbier A, et al. The impact of clerkships on students' specialty preferences: what do undergraduates learn for their profession? Med Educ 2008;42:554-62.

25. Nicholson S, Hastings AM, McKinley RK. Influences on students career decisions concerning general practice: a focus group study. Br J Gen Pract 2016;66:e768-e775.

26. Fletcher E, Abel GA, Anderson R, et al. Quitting patient care and career break intentions among general practitioners in South West England: findings of a census survey of general practitioners. BMJ Open 2017;7:e015853.

27. Braun V, Clarke V. Using thematic analysis in psychology. Qual Res Psychol 2006;3:77-101.

28. General Medical Council. The State of Medical Education and Practice in the UK, 2012.

29. Lambert TW, Smith F, Goldacre MJ. Trends in attractiveness of general practice as a career: surveys of views of UK-trained doctors. Br J Gen Pract 2017;67:e238-e247.

30. Shadbolt N, Bunker J. Choosing general practice-a review of caree choice determinants. Aust Fam Physician 2009;38:53-5.

31. Ajaz A, David R, Brown D, et al. BASH: badmouthing, attitudes and stigmatisation in healthcare as experienced by medical students. BJPsych Bull 2016;40:97-102.

32. Harding A, Rosenthal J, Al-Seaidy M, et al. Provision of medical student teaching in UK general practices: a cross-sectional questionnaire study. Br J Gen Pract 2015;65:e409-e417.

33. Smith F, Lambert TW, Goldacre MJ. Factors influencing junior doctors' choices of future specialty: trends over time and demographics based on results from UK national surveys. $J R$ Soc Med 2015;108:396-405.

34. Lloyd JR, Leese B. Career intentions and preferences of GP registrars in Yorkshire. Br J Gen Pract 2006;56:280-82.

35. McDonald $\mathrm{P}$, Jackson $\mathrm{B}$, Alberti $\mathrm{H}$, et al. How can medical schools encourage students to choose general practice as a career? $\mathrm{Br} \mathrm{J}$ Gen Pract 2016:66:292-3.

36. Health Education England. By choice-not by chance: Health Education England and Medical Schools Council. 2016.

37. Williamson MI, Wilson R, McKechnie R, et al. Does the positive influence of an undergraduate rural placement persist into postgraduate years? Rural Remote Health 2012;12.

38. Pfarrwaller E, Sommer J, Chung C, et al. Impact of interventions to increase the proportion of medical students choosing a primary care career: a systematic review. J Gen Intern Med 2015;30:1349-58.

39. Verma P, Ford JA, Stuart A, et al. A systematic review of strategies to recruit and retain primary care doctors. BMC Health Serv Res 2016;16:126.

40. Marchand $\mathrm{C}$, Peckham S. Addressing the crisis of GP recruitment and retention: a systematic review. Br J Gen Pract 2017;67:e22 $7-\mathrm{e} 237$. 